\title{
Penerapan Prinsip Kerja Sama Pada Tuturan Yang Mengandung Alih Kode Dalam Komunikasi Karyawan Biro Perjalanan Wisata Di Kabupaten Badung, Bali
}

\author{
Kadek Deco Widi Permana*, Ni Made Andry Anita Dewi \\ Program Studi Sastra Jepang Fakultas Ilmu Budaya Universitas Udayana \\ ${ }^{1}$ [kadekdeco7@yahoo.com.com], ${ }^{2}$ [andry_anita@unud.ac.id], \\ Denpasar, Bali, Indonesia
}

\begin{abstract}
Abstrak
Penelitian ini bertujuan untuk mengetahui penerapan prinsip kerja sama dalam komunikasi karyawan Biro Perjalanan Wisata di Badung. Teori yang digunakan adalah teori prinsip kerja sama dari Grice dan teori alih kode oleh Wardhaugh. Metode dan teknik pengumpulan data adalah metode simak dan teknik sadap. Metode penelitian dalam analisis data adalah deskriptif kualitatif. Tahap penyajian hasil analisis adalah metode informal. Berdasarkan hasil analisis, ditemukan lima buah data yang termasuk alih kode jenis situational code switching. Dalam penelitian ini ditemukan 1 data pematuhan maksim kuantitas, 1 data pematuhan maksim kualitas, 1 data pematuhan maksim relevansi, 1 data pelanggaran maksim relevansi, dan 1 data pematuhan maksim pelaksanaan.
\end{abstract}

Kata kunci: alih kode, maksim, penerapan prinsip kerja sama

\begin{abstract}
This research determine the application of the principles of cooperation behind the communication of Travel Agents employees in Badung. This research used theory of cooperation principles by Grice and code switching theory by Wardhaugh. The methods and techniques used in data collection are observation methods and tapping techniques. For data analysis are descriptive qualitative methods and descriptive techniques. The data presentation stage used an informal method. The results obtained in this research are 5 pieces of data including the type of situational code switching. In this research was found that 1 data on the application of the maxim of quantity, 1 data as a form of application of the maxim of quality, 1 data on the application of the maxim of relevance, 1 data on the application of the maxim of relevance, and 1 data on the application of the maxim of implementation.
\end{abstract}

Keywords: code switching, maxim, application of the principle of cooperation

\section{Pendahuluan}

Prinsip kerja sama merupakan bentuk kerja sama antara penutur yang bertujuan untuk mendapatkan informasi yang jelas antar penutur. Kushartanti, dkk (2007) menyatakan bahwa penutur dalam berkomunikasi harus berusaha agar apa yang dikatakan relevan dengan situasi di dalam percakapan itu, jelas dan mudah dipahami oleh mitra tuturnya.

Kaidah - kaidah kajian pragmatik disebut prinsip kerja sama. Grice dalam bukunya Logic and Conversation (1975:45-47), menyatakan bahwa prinsip kerja sama 
terdiri dari empat macam yaitu maksim kuantitas, maksim relevansi, maksim kualitas, dan maksim pelaksanaan. Apabila salah satu dari prinsip kerja sama tersebut dilanggar, maka akan mengakibatkan suatu tuturan tidak dapat berjalan dengan lancar. Giri (2017) juga menyebutkan konteks sosial memegang peranan penting dalam proses komunikasi. Konteks sosial menjadi penentu dalam keberhasilan suatu tuturan dapat dipahami penutur lainnya. Wijana (1996:45) yang menyatakan bahwa tuturan yang sesuai dengan konteks yang ringkas dan masih berkaitan pada persoalan agar tidak menyita waktu lawan tutur dalam memahami tuturan. Prayitno (2010) menyebutkan perlu dipertimbangkan adanya situasi dalam menentukan maksud penutur. Mereka pada umumnya masih berpegang pada prinsip bahwa hal yang disampaikan secara lugas dan terbuka kepada mitra tutur dianggap tidak sopan.

Tuturan dalam masyarakat juga dapat menimbulkan suatu kontak bahasa. Kontak bahasa menyebabkan terjadinya persinggungan dalam penggunaan bahasa. Kontak bahasa dapat terjadi ketika penutur memiliki kemampuan menggunakan lebih dari satu bahasa (Coulmas, 2005:108). Hal seperti ini disebut dengan alih kode yaitu peralihan dari ragam bahasa 1 ke ragam bahasa lainnya yang dilakukan oleh penutur (Wardhaugh, 2006:101).

Penelitian ini mempunyai dua tujuan yaitu secara umum dan secara khusus. Secara umum penelitian ini bertujuan untuk menambah wawasan serta memperkaya pengetahuan pembaca tentang sosiopragmatik. Secara khusus penelitian ini bertujuan untuk mengetahui penerapan prinsip kerja sama pada tuturan yang mengandung alih kode dalam komunikasi karyawan Biro Perjalanan Wisata di Badung.

\section{Metode dan Teori}

\subsection{Metode Penelitian}

Data yang sudah diklasifikasikan akan dianalisis menggunakan metode deskriptif kualitatif. Selanjutnya ditambahkan penggunaan teknik deskriptif yaitu teknik yang menguraiakan pembahasan tentang bahasa yang dipaparkan menjadi bentuk kata-kata (Mahsun, 2012:257). Metode penyajian analisis data dilakukan dengan menggunakan metode informal, yakni berupa uraian kata - kata, bukan dalam bentuk angka (Sudaryanto, 2015:145). 
Objek dalam penelitian ini berupa tuturan - tuturan lisan karyawan di PT. JTB Indonesia yang sudah ditranskripkan sebagai objek penelitian dalam mendeskripsikan situasi yang terjadi dan bukan berupa angka-angka atau statistik yang membuat penelitian ini menggunakan metode kualitatif. Metode rekam dan simak digunakan dalam pengumpulan data. Hasil dari menyimak dan merekam kemudian ditranskripkan dengan cara mengelompokkan setiap ujaran.

\subsection{Teori}

Teori yang digunakan adalah teori prinsip kerja sama dari Grice (1976) yang digunakan untuk menganalisis mengenai maksim dalam penerapan prinsip kerja sama. Grice dalam bukunya Logic and Conversation (1975:45-47), menyatakan bahwa prinsip kerja sama terdiri dari empat macam yaitu maksim kuantitas, maksim relevansi, maksim kualitas, dan maksim pelaksanaan. Selain itu digunakan teori alih kode oleh Wardhaugh (2006) untuk menganalisis jenis alih kode yang digunakan karyawan Biro Perjalalanan Wisata di Badung saat berkomunikasi.

\section{Kajian Pustaka}

Berdasarkan kajian - kajian yang didapatkan, terdapat beberapa penelitian yang berkaitan dengan penelitian ini. Pertama yaitu Dewi \& Wedayanti (2019) dalam jurnalnya menyebutkan masyarakat Jepang juga cenderung menghindari untuk mengutarakan sesuatu secara terbuka dalam interaksi sosialnya. Kedua yaitu penelitian Giri (2017) yang berkontribusi dalam memberikan penjelasan tambahan mengenai respon - respon dalam bahasa Jepang.

\section{Hasil dan Pembahasan}

\subsection{Prinsip Kerja Sama}

Austin (1962) mengatakan pandangan saat bertutur seseorang dapat melakukan hal lain sekaligus. Tidak menutup kemungkinan juga terdapat adanya pelanggaran prinsip kerja sama dalam komunikasi antar penutur dalam kondisi apapun dan juga bisa terjadi dalam bahasa Jepang (Widyatmoko, 2019:8). Berikut merupakan penjelasan lebih rinci mengenai keempat maksim dari prinsip kerja sama tersebut menurut Grice. 
1. Maksim kuantitas merupakan kaidah yang mengharapkan penutur dapat membagikan informasi yang secukupnya oleh mitra tutur. Kontribusi tersebut berupa informasi yang cukup dan tidak melebihi informasi yang sebenarnya (Grice, 1975:45-47).

2. Maksim Kualitas mengharapkan tiap penutur mampu memberikan informasi sesuai keadaaan sebenarnya. Kontribusi percakapan harus berdasar pada fakta-fakta yang relevan dan juga didukung dengan bukti-bukti yang memadai (Grice, 1975:45-47). Hal ini bertujuan agar lawan tutur tidak bingung untuk memahami maksud yang disampaikan oleh penutur.

3. Maksim relevansi mewajibkan penutur untuk memberikan kontribusi yang relevan sesuai dengan situasi percakapann dan sesuai dengan topik yang dibahas (Grice, 1975:45-47).

4. Maksim pelaksanaan untuk memberikan kontribusi kepada penutur agar dapat berbicara dengan memberikan informasi yang jelas, tanpa ambigu, dan ringkas untuk dapat memberikan langkah yang benar pada lawan tutur (Grice, 1975:45-47).

\subsection{Alih Kode}

Menurut Kridalaksana (2001), bahasa adalah kode yang dipakai dalam komunikasi saat berinteraksi. Jadi dapat diartikan alih kode merupakan peralihan dari suatu bahasa ke ragam yang lain. Nababan (1984) mengatakan bilingual dapat disebut sebagai orang yang mampu menggunakan dua bahasa atau lebih. Penggunaan lebih dari dua bahasa yang berbeda dan juga penguasaan dialek - dialek juga berperan penting dalam sebuah komunikasi (Rusyana, 1988: 2). Ragam bahasa maupun bahasa itu sendiri merupakan suatu kode yang penutur gunakan dalam suatu tindak tutur. Wardhaugh menyebutkan alih kode ada dua yaitu.

\section{Metaphorical code switching}

Metaphorical code switching adalah peralihan bahasa jika ada perubahan topik pembicaraan yang melibatkan penutur tersebut. Alih kode ini terjadi akibat adanya makna yang ditambahkan dalam tuturan yang digunakan untuk merespon lawan tutur.

\section{Situational code switching}

Situational code switching adalah jenis alih kode yang terjadi karena pengaruh keadaan atau situasi pada sebuah tuturan. Saifudin (2010) menambahkan bahwa faktor 
jarak sangat memengaruhi proses komunikasi. Jarak yang disebutkan yaitu status sosial, usia, dan jabaran.

Berikut merupakan penerapan yang terbagi menjadi penerapan dan pelanggaran dari empat maksim yang ada.

a. Maksim Kuantitas

(1) Noma：“ごめんなさい”は言わない。それは友達だけ

Arini ：ああほとんど使わなね。“申し訳ございません”のほうが使いますね。 “さようなら”も言わない。

Noma : Ya, tidak biasa dipakai, karena “さようなら” itu artinya selama lama tidak ketemu. Tapi ada juga tiap daerah yang pakai sayounara. Tapi kalau menurut saya lebih cocok pakai “じや、また”。

Arini : そうですね。“さようなら”は本当の長い間会わない。 ですけど、“じゃまた”は明日とか ...

Noma :そうそう、tapi kalau setahun dua tahun tidak mau ucapkan “さようなら”.

Noma : "Gomen nasai" wa iwanai. Sore wa tomodachi dake...

Arini : Aa hotondo tsukawanaine. "Moushiwake gozaimasen" no hou ga tsukaimasune. "Sayounara" mo tsukawanai.

Noma : Ya, tidak biasa dipakai, karena "sayounara" itu artinya selamalama tidak ketemu. Tapi ada juga tiap daerah yang pakai "sayounara". Tapi kalau menurut saya lebih cocok pakai "ja, mata".

Arini : Sou desune. "Sayounara" wa honto no nagai aida awanai. Desukedo, "ja mata" wa ashita toka.

Noma : Sou sou, tapi kalau setahun dua tahun tidak mau ucapkan "sayounara".

Noma : "Maaf' tidak diucapkan. Itu untuk teman saja.

Arini : Ya hampir tidak dipakai ya, lebih menggunakan "moushiwake gozaimasen"."Sayounara" juga tidak dipakai.

Noma : Ya, tidak biasa dipakai, karena "sayounara" itu artinya selama lama tidak ketemu. Tapi ada juga tiap daerah yang pakai "sayounara". Tapi kalau menurut saya lebih cocok pakai "ja mata".

Arini : Ya benar, "sayounara" itu tidak bertemu dalam jangka waktu yang lama. Tetapi kalau "ja mata" misalnya besok.

Noma : Ya ya, tapi kalau setahun dua tahun tidak mau ucapkan "sayounara". 
Data (1) merupakan tuturan yang mengandung alih kode jenis situational code switching atau alih kode yang terjadi karena perubahan situasi yang terjadi antara Noma yang merupakan karyawan berkebangsaan Jepang dan Arini karyawan berkebangsaan Indonesia. Tuturan Noma dalam merespon Arini juga mengandung pematuhan maksim kuantitas.

Arini ingin mengonfirmasi antara istilah gomen nasai dan moushiwake gozaimasen. Menurut Edisal (2010:50) "gomen nasai" lebih menunjukkan pada penyesalan dan permohonan maaf dan sering digunakan oleh perempuan. Noma merespon dengan memberikan penjelasan bahwa moushiwake gozaimasen lebih digunakan dalam situasi formal. Atiqah (2018) menyebut masyarakat Jepang juga dikenal taat terhadap peraturan sehingga sangat menjunjung norma yang ada.

b. Maksim Kualitas

(2) Arini : Suami は mancing 帰って

Misawa : そう。なんかあるじゃん、波の何だけ満潮干潮っ...

Arini : Ya, yang pasang surut itu.

Misawa : はい、たぶん purnamaまでは明日の朝行ったら purnamaまでは休み Purnamaの後また。いつもちょっと前、昨日..今日 明日しか行ってない。昨日は朝と夕方と言うか siangまた出かけ る。

Arini $\quad$ : Suami wa mancing kaette..

Misawa : Sou. Nanka aru jan, nami no nandake manchou kanchoutte...

Arini : Ya, yang pasang surut itu.

Misawa : Hai, tabun purnama made wa ashita no asa ittara purnama made yasumi. Purnama no ato mata. Itsumo sono chotto mae, kinou... Kyou wa asa shika ittenai. Kinou wa asa to yuugata to iu ka siang mata dekakeru.

Arini : Suami pulang dari mancing...

Misawa : Ya, apa itu ya, pasang surutnya air laut...

Arini : Ya, yang pasang surut itu.

Misawa : Ya, mungkin sampai purnama, kalau besok pagi pergi sampai Purnama nanti libur. Setelah purnama lagi. Sebelumnya selalu begitu, kemarin... Kalau hari ini hanya pagi saja. Kemarin pagi dan sore atau siangnya bisa pergi memancing.

Tuturan pada data (2) terjadi alih kode yang terjadi karena perubahan situasi atau situasional code switching. Arini terdengar belum yakin terhadap istilah 'manchou kanchou' yang disampaikan Misawa saat melakukan tuturan. Arini memberikan informasi terhadap istilah yang disampaikan Misawa dengan menggunakan bahasa 
Indonesia. Data (2) juga mengandung penerapan maksim kualitas yang dilakukan Arini. Tuturan Misawa yaitu, Sou. Nanka aru jan, nami no nandake manchou kanchoutte..., 'Ya, apa itu ya, pasang surutnya air laut...' direspon oleh Arini yaitu, 'Ya, yang pasang surut itu'. Respon Arini menunjukkan sebuah informasi yang diberikan sesuai dengan fakta yang diketahui Arini (Grice, 1975:46).

(3) Noma：東京とかじゃなければ、いいと思う

Arini : Iya terlalu kota

Noma : そう, terlalu ramai mungkin bingung

Arini : Iya seperti tempat saya dulu di Okayama masih ada alam, trus masyarakat sama seperti Di Bali ada teman juga.でも、東京は忙し い。

Noma :そうなの, terlalu penuh だから

Noma : Tokyo toka janakereba, ii to omou

Arini : Iya terlalu kota

Noma : Sou, terlalu ramai mungkin bingung.

Arini : Iya seperti tempat saya duludi Okayama masih ada alam, trus masyarakat sama seperti Di bali ada teman juga. Demo, Tokyo wa isogashii.

Noma : Sou nano, terlalu penuh dakara.

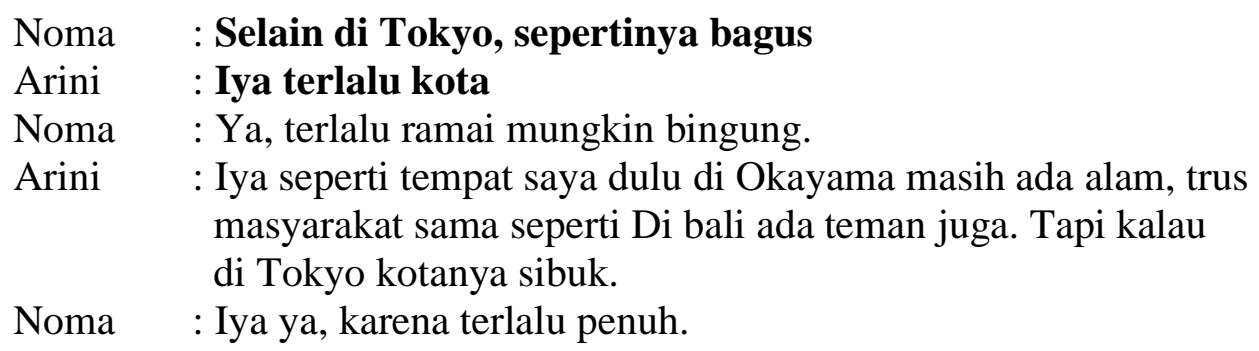

Tuturan pada data (3) mengandung situational code switching atau alih kode yang terjadi karena adanya perubahan situasi saat berkomunikasi. Arini ingin menyebut Tokyo sebagai wilayah yang padat penduduk dengan menyebutkan 'iya terlalu kota' untuk merespon saran yang diberikan Noma.

Tuturan dalam data (3) juga terdapat penerapan maksim kualitas. Dalam tuturan yang disampaikan Noma, ia memberikan saran kepada Arini tentang situasi tempat yang bagus jika ingin tinggal di Jepang. Noma bertutur yaitu, Tokyo toka janakereba, ii to omou, 'selain di Tokyo, sepertinya bagus'. Pada tuturan yang disampaikan Arini untuk merespon tuturan yang disampaikan Noma merupakan sebuah kontribusi yang diberikan berdasarkan fakta dan sesuai bukti-bukti yang mendukung (Grice, 1975:45-47). 
c. Maksim Relevansi

(4) Noma : “失礼します”バリにはあるかも、”すみませ 失礼します, permisi”

Arini : そう、間違いときも”しつれいいたしました”

Noma : "Silahkan masuk" juga. Maknanya luas ya

Noma : "Shitsurei shimasu” bari ni aru kamo, "sumimasen shitsurei shimasu, permisi"

Arini : Sou, machigai toki mo "shitusurei itashimashita"

Noma : "Silahkan masuk" juga. Maknanya luas ya

Noma : "Permisi" di Bali juga ada sepertinya "maaf, permisi"

Arini : Ya, saat salah juga pakai "maaf permisi"

Noma : "Silahkan masuk" juga. Maknanya luas ya.

Tuturan pada data (4) terjadi antara Arini yang merupakan karyawan berkebangsaan Indonesia dengan Noma yang merupakan karyawan berkebangsaan Jepang. Dalam komunikasi antara Noma dan Arini mengandung alih kode jenis situational code switching atau alih kode yang terjadi karena adanya perubahan situasi saat berkomunikasi. Tuturan Noma beralih kode dari bahasa Jepang ke bahasa Indonesia yaitu 'silahkan masuk juga. Maknanya luas ya' terjadi karena situasi Noma ingin memberikan informasi tambahan dengan bahasa Indonesia agar Arini lebih mudah memahaminya.

Tuturan Noma dan Arini juga mengandung penerapan maksim relevansi. Pada tuturan sebelumnya mereka saling memberi informasi mengenai makna kata "shitsurei shimasu" dan waktu penggunaan kata "shitsurei shimasu”. Shitsurei berarti 'kurang hormat, kurang sopan atau tidak sopan' (Matsuura: 2005:945). Suatu kata memiliki fungsi berbeda ketika disampaikan kepada kawan bicara (Asrini, 2010). Informasi tambahan yang diberikan Noma sangat jelas bahwa informasi mengenai kata "shitsurei shimasu” sangat relevan untuk merespon tuturan Arini.

d. Maksim Pelaksanaan

(5) Arini : 学校行ってないけど、英語と日本語はできるね。

Noma : Yang pentingnya dipakai gitu ya.

Arini : だからも勇気おもって、話すしかない。私みたい、学校行ってない けど毎日日本人と一緒にスタンバイしますから日本語を使います。

Arini : Gakko ittenai kedo, Eigo to Nihongo wa dekirune.

Noma : Yang pentingnya pake gitu ya.

Arini : Dakara mo yuuki o motte, hanashi shika nai. Watashi mitai, gakko ittenai kedo mai nichi Nihon jin to isshou ni sutenbaishimasu kara 


\title{
Nihongo o tsukaimasu.
}

\author{
Arini : Walaupun tidak sekolah, tapi bisa bahasa Inggris dan bahasa \\ Jepang ya. \\ Noma : Yang pentingnya dipakai gitu ya. \\ Arini : Hanya dengan keberanian berbicara saja. Menurut saya, meskipun \\ tidak sekolah, tetapi karena setiap hari bekerja dengan orang \\ Jepang jadi menggunakan bahasa Jepang.
}

Pada data (5) terjadi sebuah alih kode oleh Noma dari bahasa Jepang ke bahasa Indonesia. Noma melakukan respon terhadap tuturan Arini dengan beralih kode ke bahasa Indonesia yaitu, 'yang pentingnya dipakai gitu ya'. Noma ingin situasi dalam bertutur dengan Arini terkesan santai. Noma beralih kode dari bahasa Jepang ke bahasa Indonesia merupakan jenis situational code switching (Wardaugh ,1986).

Tuturan antara Noma dan Arini pada data (5), juga terdapat penerapan maksim pelaksanaan yang dilakukan Noma. Informasi yang diberikan Arini yaitu, 'gakko ittenai kedo, Nihongo wa dekiru ne, 'walaupun tidak sekolah, tetapi bisa bahasa Jepang ya'. Noma merespon informasi yang disampaikan Arini dengan persetujuan yaitu, 'yang pemtingnya dipakai gitu ya'. Respon yang perlihatkan terlihat Noma menyetujui atas informasi yang diberikan Arini.

\section{Simpulan}

Setiap komunikasi, respon penutur sangat menentukan kelancaran saat berkomunikasi seperti adanya alih kode dilakukan oleh karyawan PT. JTB Indonesia. Terdapat 2 jenis alih kode yang terdapat dalam penelitian ini yaitu metaphorical code switching dan situational code switching. Penelitian ini menganalisis 5 buah data dan ditemukan bahwa semua data yang terdapat dalam penelitian ini termasuk alih kode jenis situational code switching atau alih kode yang terjadi karena pengaruh keadaan dan situasi dalam sebuah tuturan. Perubahan situasi terjadi karena adanya karyawan yang berkebangsaan Indonesia dan juga karyawan berkebangsaan Jepang.

Selain menganalisis alih kode, pada penelitian ini juga menganalisis penerapan prinsip kerja sama yang timbul dari tuturan antar karyawan. Prinsip kerja sama dibagi menjadi empat yaitu, maksim kualitas, maksim relevansi, maksim pelaksanaan, dan maksim kuantitas. Dalam 5 data dalam penelitian ini ditemukan 1 data pematuhan 
maksim kuantitas, 1 data pematuhan maksim kualitas, 1 data penerapan maksim relevansi, 1 data pelanggaran maksim relevansi, dan 1 data penerapan maksim pelaksanaan.

Penelitian selanjutnya diharapkan mampu menganalisis kajian sosiopragmatik lainnya untuk bisa menambah referensi bagi mahasiswa Sastra Jepang dalam mencari kajian penelitian. Selain itu, faktor yang melatarbelakangi terjadinya alih kode atau prinsip kerja sama bisa menjadikan penelitian selanjutnya memiliki sudut pandang yang berbeda.

\section{Daftar Pustaka}

Asrini, D. P. (2020). Perilaku Aisatsu Masyarakat Jepang (Studi Kasus di Kalangan Mahasiswa Jepang). Chi'e: Journal of Japanese Learning and Teaching, 8(1), 4356.

Atiqah, A. N., \& Salindri, Y. A. (2018). Prinsip Kesantunan Berbahasa Antara Pemandu Wisata Dan Wisatawan Jepang Di Candi Prambanan (Kajian Analisis Pragmatik). Kepariwisataan: Jurnal Ilmiah, 12(01), 65-78.

Austin, J. (1961). How to Do Things with Words. Oxford University Press.

Coulmas, Florian. (2005). Sociolinguistics: Study of Speakers Choice. Cambridge University Press.

Dewi, N. M. A. A., \& Wedayanti, N. P. L. (2019). Kesantunan Berbahasa yang Tercermin dalam Aimai Hyogen. Pustaka: Jurnal Ilmu-Ilmu Budaya, 19(2), 89-93.

Edisal. (2010). Tutur Kata Manusia Jepang. Kayupasak.

Giri, N.L.K.Y. (2017). Variasi Respons Dalam Analisis Percakapan Bahasa Jepang. The $8^{\text {th }}$ International Seminar on Austronesian and Non-Austronesian Language and Literature in Indonesia, 677-684.

Grice. (1975). Logic and conversation. Oxford University Press.

Kridalaksana, Harimurti. (2008). Kamus Linguistik. Gramedia Pustaka Utama.

Mahsun. (2012). Metode Penelitian Bahasa: Strategi, Metode, dan Tekniknya. Rajawali Pers.

Matsuura, Kenji. (2005). Kamus Jepang-Indonesia. Gramedia Pustaka Utama.

Nababan, P.W.J. (1984). Sosiolinguistik Pengantar. Gramedia Pustaka Utama

Prayitno, H. J. (2010). Perwujudan Prinsip Kerjasama, Sopan Santun, dan Ironi Para Pejabat dalam Peristiwa Rapat Dinas di Lingkungan Pemkot Berbudaya Jawa. Jurnal Kajian Linguistik dan Sastra, 22(1), 30-46.

Rusyana, Yus. (1988). Perihal Kedwibahasaan (Bilingualisme). Depdikbud. 
Saifudin, A. 2010. Analisis Pragmatik variasi kesantunan tindak tutur terima kasih bahasa jepang dalam film beautiful life karya Kitagawa Eriko. Lite: Jurnal Bahasa, Sastra, dan Budaya, 6(2), 172-181.

Sudaryanto. 2015. Metode dan Teknik Analisis Bahasa. Duta Wacana University.

Wardhaugh, Ronald. 2006. An Introduction to Sociolinguistic. Blackweel.

Widyatmoko, A. 2019. Pelanggaran Prinsip Kerjasama Dalam Percakapan Bahasa Jepang Pada Anime "Kimi No $\mathrm{Na} \mathrm{Wa"} \mathrm{Karya} \mathrm{Makoto} \mathrm{Shinkai} \mathrm{(Doctoral} \mathrm{dissertation,}$ Universitas Brawijaya).

Wijana, Dewa Putu. 1996. Dasar-Dasar Pragmatik. Andi Offset 